\title{
March Critical Care Journal Club: Sequelae of Critical Care
}

We focused on the topic of long-term sequelae of acute respiratory failure requiring mechanical ventilation.

Our discussion panel included the fellows, many of our faculty including Drs. Robbins, Mathew, Singarajah, Thomas, Rinne, Garcia-Orr, and Nair, and invited guests from Palliative Care Medicine: Dr. Carleton, and Julie Lehn (from the VAMC and BGSMC respectively).

The long term clinical outcomes of two groups of patients were examined. The first group was comprised of survivors of acute respiratory distress syndrome (ARDS) requiring mechanical ventilation of any duration. Although the short-term mortality of ARDS has improved, previously unrecognized long-term sequelae have become a focus of research. Studies have now shown that significant depression, cognitive deficits similar in magnitude to those of mild Alzheimer's, and post-traumatic stress disorder (PTSD) each occur in approximately $25-30 \%$ of these patients (1-4). PTSD continues in about a quarter of patients even out to eight years after discharge (2). Functional disability is demonstrable up to 5 years after discharge, even in younger patients (4). Although pulmonary function typically normalize, all patients - even young patients with relatively mild ARDS - report subjective physical weakness out to five years post discharge (4). Twenty-seven percent of the patient's family members will also suffer depression and PTSD in the aftermath of an ICU admission for ARDS.

The second group of patients are those who require mechanical ventilation for greater than 21 days, or who require tracheostomy. The term "Chronic Critical Illness" has been coined to describe this group of patients, who comprise 5-10\% of ICU admissions (1). These patients are often "trached and PEGed" and transferred to skilled nursing facilities after ICU care is completed. It is estimated that there are approximately 100,000 such patients in the United States at any point in time. We all recognize the clinical manifestations that many of these patients share: persistent delirium, critical illness weakness, musculoskeletal catabolism, skin breakdown, dysphagia/anorexia/malnutrition, infection/colonization with healthcare-associated microorganisms, and prolonged renal failure, among others.

We often feel a sense of limited success when such a patient survives the ICU, but outcome studies suggest a very poor outlook for meaningful recovery $(5,6)$. Less than half of these patients will ever be liberated from the ventilator, and almost never after more than 60 days of mechanical ventilation dependence. At 6 months, $75 \%$ will be dead or institutionalized. By a year, only about $10 \%$ will be living independently at home. Chronically critically-ill patients with age $>50$, thrombocytopenia, and need for ongoing vasopressors or dialysis suffer $97 \%$ 1-year mortality. $84 \%$ of family caregivers of survivors end up having to quit their jobs or significantly cut back work hours in order to provide support - many of these family care givers suffer depression and physical health deterioration. A $\$ 3.5$ million dollar direct cost is incurred per independently functioning survivor of chronic critical illness at 1 year. 
We do not do a good job communicating these grim statistics to our patients and their families. Up to $90 \%$ of families of chronically critically ill patients report that they received no information about possible functional dependency or 1-year mortality at hospital discharge. Perhaps this is because it is hard for us to accept the futility of much of what we do. Besides our best efforts to minimize sedation, ambulate and extubate patients as rapidly as possible, and prevent iatrogenic infections, there is little of proven value to prevent or treat chronic critical illness.

Notwithstanding these depressing statistics there are things we can do to mitigate both the physical and psychological complications which result from the acute phase of the critical illness. The first, as noted above, is to simply take an interest in the chronic phase of critical illness by following through on the outcomes of our patients. It is well demonstrated that the actuarial age-and-sex adjusted survival for critical illness takes between two and five years to return to normal, depending on the disease process. It is shorter for surgical patients and longer for medical patients (who are frequently suffering the end result of chronic organ system failure, for which there is limited curability). The fragmentation of disposition in modern healthcare means that once these patients have left the intensive care unit their ongoing mortality and morbidity is invisible to us unless we take active steps to check in on their condition. It follows, incidentally, that it is not realistic to expect excellent survival statistics for long term acute care facilities when these institutions are taking from acute ICU's the burden of a population predestined to have a high mortality and morbidity.

Intensive care follow up clinics, although almost non existent in the United States, largely for reasons of reimbursement, have become widespread in other parts of the world. In the United Kingdom, for example, the National Health Service Initiative "Intensive care without walls" was launched in 2000. During this relatively early phase of development, research has been quite plentiful and has largely consisted of characterizing the problems described above. Earlier diagnosis of psychological sequelae such as post-traumatic stress disorder, cognitive impairment, depression, sleep derangement and also the physical sequelae such as deconditioning and chronic pain have allowed earlier outpatient treatment-which has, unsurprisingly, been shown to improve outcomes. However, with increasing rapidity management of the "back end" of critical illness-the chronic disease state- is moving closer and closer to the "front end" as we realize quite how tightly they are connected.

The first report of mobilization in mechanically ventilated patients was published only in 2007 but since then a steady series has begun to appear in the literature (7). In 2009 Schweikert et al (8) demonstrated that early physical and occupational therapy during ventilation resulted in a return to independent functional status at hospital discharge in $29(59 \%)$ of patients compared with 19 (35\%) patients in the control group $(p=0.02$; odds ratio 2.7). Moreover, ICU delirium days were reduced by $50 \%$ (2.0 days vs. 4.0 days, $P=.03$ ) in spite of no differences in sedatives administered and more ventilatorfree days (23.5 days, $p=0.05$ ) during the 28-day follow-up period than did controls. The early mobilization strategy led to a 1.7 -fold increase in patients who were functionally 
independent when they left the hospital ( $59 \%$ vs. $35 \%, P=.02)$. Finally, more patients in the early mobilization group went directly home after hospitalization than in the control group ( $43 \%$ vs. $24 \%, P=.06$ ). Of note, there was just one serious adverse event in 498 therapy sessions and this consisted of arterial oxygen desaturation to less than $80 \%$.

In 2013 the BRAIN-ICU study mentioned above demonstrated that longer duration of delirium was associated with worse cognition and executive function scores at 3 and 12 months post discharge (4). It is increasingly clear that policies which result in minimization of total sedative dose not only reduce delirium but also promote early mobilization and better REM sleep. Normal fatigue from early mobilization results in the virtuous cycle of not only better natural REM sleep with less GABA agonist needs but thereby a reduced incidence of delirium. Less delirium is associated with better long term psychological outcomes and early mobilization is associated with better long term physical outcomes. These factors are intimately interconnected both between each other in the ICU and also with the long term outcomes once the patient goes home. It simply makes sense. While on the one hand we need to take ownership of the truly terrible long term course of critical illness, on the other we should embrace the possibility of doing something significant to improve it even though we can't easily see it unless we start to look. At the present time, it is hiding in plain sight.

The ensuing discussion led us to several conclusions. We felt that in cases of acute respiratory failure requiring short-term mechanical ventilation, patients and their families should be advised of the high risk of persistent neurocognitive, psychological and functional disability and offered a venue for appropriate follow-up after discharge. Establishment of a Critical Care follow-up clinic is worth considering in this regard.

Further measures are required in cases of prolonged ventilator dependence. This starts with the recognition that tracheostomy is most often NOT a step towards recovery, but more likely a sign that the patient will never regain independent function again. In fact, the prognosis in patients with chronic critical illness is often worse than most forms of cancer in terms of mortality and quality of life.

In most patients who do not liberate from the ventilator within three weeks, a frank discussion of the grim long-term outcomes should ensue before tracheostomy is performed. It is likely that some patients and families might chose other alternatives, such as withdrawal of life support, if given an accurate picture of the poor chance they will survive or ever regain independence. Palliative care medicine consultation should be strongly considered in all such patients. The Society of Critical Care Medicine has a helpful brochure with information for patients and families in regard to Chronic Critical Illness available on their website. Good bedside care of patients with chronic critical illness and their families will likely reduce unnecessary suffering while reducing the cost of healthcare.

Robert A. Raschke, MD and Huw Owen-Reece, MD Banner Good Samaritan Medical Center 


\section{References}

1. Nelson JE, Cox CE, Hope AA, Carson SS. Chronic Critical Illness. Am J Respir Crit Care Medicine. 2010;182:446-454. [CrossRef] [PubMed]

2. Davydow DS, Desai SV, Needham DM, Bienvenu J. Psychiatric morbidity in survivors of the acute respiratory distress syndrome: A systematic review. Psychosomatic Medicine. 2008;70:512-9. [CrossRef] [PubMed]

3. Herridge MS, Tansey CM, Matte A, Tomlinson G, et al. Functional disability 5 years after acute respiratory distress syndrome. NEJM. 2011;364:1293-1305. [CrossRef] [PubMed]

4. Pandharipande PP, Girard TD, Jackson JC, Morandi A, et al. Long-term cognitive impairment after critical illness. NEJM. 2013;369:1306-16. [CrossRef] [PubMed]

5. Carson, SS, Garrett J, Hanson LC, Lanier J et al. A prognostic model for one-year mortality in patients requiring prolonged mechanical ventilation. Crit Care Medicine. 2008;36:2061-69. [CrossRef] [PubMed]

6. Wright JC, Plenderleith L, Ridley SA. Long-term survival following intensive care: subgroup analysis and comparison with the general population. Anaesthesia. 2003;58(7):637-42. [CrossRefl [PubMed]

7. Bailey P, Thomsen GE, Spuhler VJ, et al. Early activity is feasible and safe in respiratory failure patients. Crit Care Med. 2007;351:139-145. [CrossRef] [PubMed]

8. Schweickert WD, Pohlman MC, Pohlman AS, et al. Early physical and occupational therapy in mechanically ventilated, critically ill patients: a randomized controlled trial. Lancet. 2009; 373(9678):1874-82. [CrossRef] [PubMed] 